Delft University of Technology

\title{
An Accurate BJT-Based CMOS Temperature Sensor With Duty-Cycle-Modulated Output
}

Wang, Guijie; Heidari, Ali; Makinwa, Kofi; Meijer, Gerard

DOI

10.1109/TIE.2016.2614273

Publication date

2017

Document Version

Accepted author manuscript

Published in

IEEE Transactions on Industrial Electronics

\section{Citation (APA)}

Wang, G., Heidari, A., Makinwa, K., \& Meijer, G. (2017). An Accurate BJT-Based CMOS Temperature Sensor With Duty-Cycle-Modulated Output. IEEE Transactions on Industrial Electronics, 64(2), 1572-1580. https://doi.org/10.1109/TIE.2016.2614273

\section{Important note}

To cite this publication, please use the final published version (if applicable).

Please check the document version above.

\section{Copyright}

Other than for strictly personal use, it is not permitted to download, forward or distribute the text or part of it, without the consent of the author(s) and/or copyright holder(s), unless the work is under an open content license such as Creative Commons.

\section{Takedown policy}

Please contact us and provide details if you believe this document breaches copyrights.

We will remove access to the work immediately and investigate your claim. 


\title{
An Accurate BJT-Based CMOS Temperature Sensor with Duty-Cycle-Modulated Output
}

\author{
Guijie Wang, Ali Heidari, Kofi A.A. Makinwa, Fellow Member IEEE, \\ and Gerard C.M. Meijer, Senior Member IEEE
}

\begin{abstract}
This paper describes the design of a precision BJT-based temperature sensor implemented in standard $0.7 \mu \mathrm{m}$ CMOS technology. It employs substrate PNPs as sensing elements, which makes it insensitive to the effects of mechanical (packaging) stress and facilitates the use of low-cost packaging technologies. The sensor outputs a duty-cycle-modulated signal, which can easily be interfaced to the digital world and, after low-pass filtering, to the analog world. In order to eliminate errors caused by component mismatch, chopping and Dynamic Element Matching (DEM) techniques have been applied. The required component shuffling was done concurrently rather than sequentially, resulting in a fast DEM scheme that saves energy without degrading accuracy. After a single-temperature trim, the sensor's inaccuracy is $\pm 0.1^{\circ} \mathrm{C}$ $\left(-20^{\circ} \mathrm{C}\right.$ to $\left.60^{\circ} \mathrm{C}\right)$ and $\pm 0.3^{\circ} \mathrm{C}\left(-45^{\circ} \mathrm{C}\right.$ to $\left.130^{\circ} \mathrm{C}\right)$, respectively. Measurements of sensors in different packages show that the package-induced shift is less than $0.1^{\circ} \mathrm{C}$. Measurements of 8 sensors over 367 days show that their output drift is less than $6 \mathrm{mK}$. While dissipating only $200 \mu \mathrm{W}$, the sensor achieves a resolution of $3 \mathrm{mK}$ ( $\mathrm{rms})$ in a $1.8 \mathrm{~ms}$ measurement time, and a state-of-the-art resolution Figure of Merit (FoM) of 3.2pJK ${ }^{2}$. This combination of high accuracy, high resolution, high speed and low energy consumption makes this sensor suited for commercial and industrial applications.
\end{abstract}

Index Terms - CMOS Temperature Tensor, Chopping, Dynamic Element Matching (DEM), Duty-Cycle-Modulation, One-Point Trim.

\section{INTRODUCTION}

$\mathrm{O}$ NE of the first smart sensors that could be read out by simple microcontrollers was a temperature sensor that generated a duty-cycle modulated output signal [1], and which was implemented in BICMOS technology. Nowadays, a

Manuscript received February 4 2016; revised May 26, 2016; accepted August 22, 2016. This work was supported by Smartec B.V the Netherlands and Electronic Instrumentation Laboratory, Delft University of Technology.

Guijie Wang is with Smartec B. V. The Netherland and Electronic Instrumentation Laboratory, Delft University of Technology, the Netherlands (e-mail: g.wang@tudelft.nl).

Ali Heidari is with Smartec B. V. The Netherland, Electronic Instrumentation Laboratory, Delft University of Technology, the Netherlands and Guilan University, Iran (e-mail: A.Heidari@tudelft.nl).

Kofi A.A. Makinwa is with Electronic Instrumentation Laboratory, Delft University of Technology, the Netherlands (e-mail: K.A.A.Makinwa@tudelft.nl).

Gerard C.M. Meijer is with Electronic Instrumentation Laboratory, Delft University of Technology, the Netherlands and Sensart B.V. the Netherlands (e-mail: G.C.M.Meijer@tudelft.nl). wide range of smart temperature sensors are available in lowcost CMOS technology [2] - [5]. However, it still make sense to design sensors with duty-cycle modulated outputs, because such signals have a number of useful and important features:

a) Usability in both analog and digital systems: Compared to the more widely used sigma-delta modulators, an attractive feature of duty-cycle modulators is that they can be easily and robustly connected to digital systems, such as microcontrollers, as well as to analog systems, such as thermostats ([6], chapter 10).

b) Low energy consumption: Often, the interface circuitry of a smart temperature sensor consumes more energy than the actual sensor itself. It then makes sense to perform the required signal processing in an external microcontroller as much as possible, so that the sensor's energy consumption (and self-heating) is minimized.

Recently, a CMOS smart temperature sensor with a dutycycle-modulated-output signal has been presented [10]. In this paper, more details are disclosed together with the results of extensive measurements, which were done to characterize the new sensor for industrial applications. Compared to an earlier design with a duty-cycle-modulated-output [1], the main performance objectives of the new design are as follows:

a. Better accuracy and lower sensitivity to packaging shift.

b. More resolution at even higher acquisition rates.

c. Lower energy consumption per measurement.

d. Better long-term stability.

Early temperature sensors with duty-cycle-modulated outputs [1], [11], achieved good accuracy by exploiting the benefits of bipolar or BiCMOS technology, e.g. good component matching and the availability of high-performance Bipolar Junction Transistors (BJTs). Compared to CMOS technology, however, these benefits came at the expense of higher manufacturing cost. Although the analog performance of CMOS technology is arguably poorer, later work has demonstrated that it can also be used to realize accurate temperature sensors [12] - [16]. These sensors employ dynamic error-correction techniques, such as chopping, correlated-double sampling and Dynamic Element Matching (DEM) to mitigate the effects of component mismatch, and employ compensation schemes to reduce the effects of the low current gain of the available substrate PNPs [12], [16]. Straightforward implementation of such techniques would require complex circuitry and thus too much chip area. Furthermore, the required signal processing would then require hundreds of periods of the output signal, leading to a low data rate and high energy consumption. In this paper, it will be shown, how the required signal processing can be sped 
up, so that data rate and energy consumption can be minimized without losing performance.

In CMOS technology, the temperature-sensing elements can be BJTs [12] - [16], MOSFETs [17] - [18] or resistors [19] [22]. The best accuracy has been achieved with BJTs after a one-point trim [12] - [16]. On the other hand, sensors based on MOSFETs or resistors can operate from low supply voltages, even below $1 \mathrm{~V}$, but achieve lower accuracy, and sometimes even require multi-point trimming [21] - [22], thus significantly increasing calibration costs. Furthermore, the substrate PNPs available in CMOS technology, turn out to be quite insensitive to the mechanical stress induced by lowcost plastic packaging [23] - [25]. Consequently, excellent long-term stability and robustness to extreme thermal cycling can be achieved.

The sensor employs a continuous-time duty-cycle modulator whose system-level design is described in Section II. This is followed, in Section III, by a description of a selfclocked chopping and DEM scheme that averages component mismatch over several periods of the modulator's output. Straightforward application of this scheme would require 256 periods. However, it will be shown how this can be reduced to just eight without significant loss of accuracy. Details about the circuit implementation and signal processing are presented in Section IV and V, respectively. Measurement results are described in Section VI.

\section{BASIC DESIGN}

For reasons of simplicity, small chip size, low energy consumption and compatibility, the basic operation of the CMOS temperature sensor (Fig. 1) is chosen to be the same as that of previous designs [1], [11]. Under the control of a Schmitt trigger (ST), a capacitor $C$ is periodically charged by a current $I_{1}$ up to a threshold voltage $V_{2}$ and then discharged by a current $I_{2}$ down to a threshold voltage $V_{1}$ (Fig. 1 (a)). As can be deduced from the timing diagram shown in Fig. 1 (b), the duty-cycle $D$ of the resulting output signal equals:

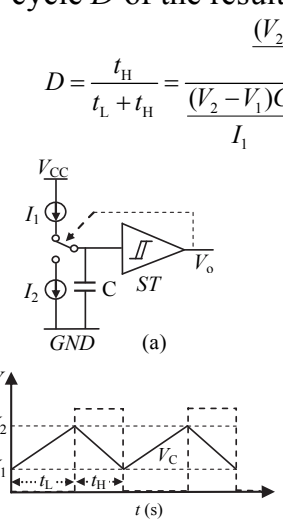

(b)
Fig. 1. The operation principle of the temperature sensor. (a) Basic principle; (b) the voltage across the capacitor C; (c) various (extrapolated) currents as a function of temperature.

It should be noted that the value of $D$ is independent of the exact value of the ST's threshold voltages $V_{1}$ and $V_{2}$ and of the capacitance $C$. The two currents $I_{1}$ and $I_{2}$ are designed to be temperature dependent: In its simplest implementation, $I_{1}$ is linearly proportional to absolute temperature (PTAT), while $I_{2}$ is complementary-to-absolute-temperature (CTAT) (Fig. 1 (c)). Furthermore, if the sum $I_{\text {ref }}=I_{1}+I_{2}$ is designed to be temperature independent (as indicated in Fig. 1 (c)), then $D$ will be a linear function of temperature.

In a CMOS process, the CTAT current $I_{2}$ can be derived from the base-emitter voltage $V_{\mathrm{BE}}$ of a substrate PNP, while $I_{1}$ can be derived from the difference $\Delta V_{\mathrm{BE}}$ between the baseemitter voltages of two appropriately biased PNPs. However, as shown in Fig. 1 (c), the resulting duty-cycle $D$ will then vary by only about $30 \%$ over the desired temperature range: $-45^{\circ} \mathrm{C}$ to $130^{\circ} \mathrm{C}$.

To increase the dynamic range of $D$, the currents $I_{1}$ and $I_{2}$ can be implemented as the combination of a PTAT current $I_{\text {PTAT }}$ and a CTAT current $I_{\text {CTAT }}$ [11], such that

$$
\begin{aligned}
& I_{1}=3 I_{\mathrm{PTAT}}-0.5 I_{\mathrm{CTAT}} \\
& I_{2}=I_{\mathrm{CTAT}}-I_{\mathrm{PTAT}}
\end{aligned}
$$

Fig. 2. The charge and discharge current in this design.

As in [11], the sum $I_{\text {ref }}$ of the charging and discharging currents, i.e. $2 I_{\mathrm{PTAT}}+0.5 I_{\mathrm{CTAT}}$, was designed to have a slightly positive temperature coefficient, which effectively compensates the curvature in $V_{\mathrm{BE}}$. As shown in Fig. 2, this scheme ensures that $D$ now varies from about $10 \%$ to $90 \%$ over the desired temperature range: $-45^{\circ} \mathrm{C}$ to $130^{\circ} \mathrm{C}$.

Fig. 3 shows a simplified block diagram of the actual CMOS sensor. Substrate bipolar PNP transistors $Q_{1}$ and $Q_{2}$ are biased at a 1:9 current-density ratio, and an Op-amp ( $\left.\mathrm{OP}_{1}\right)$ forces the resulting voltage $\Delta V_{\mathrm{BE}}=(k T / q) \ln (9)$ across a resistor $R_{\mathrm{PTAT}}$ to generate a PTAT current $I_{\mathrm{PTAT}}=\Delta V_{\mathrm{BE}} / R_{\mathrm{PTAT}}(\sim 1 \mu \mathrm{A}$ at room temperature). Similarly, $\mathrm{OP}_{2}$ and resistor $R_{\mathrm{BE}}$ convert the base-emitter voltage $V_{\mathrm{BE} 3}$ of $Q_{3}$ into a CTAT current $I_{\mathrm{CTAT}}=V_{\mathrm{BE} 3} / R_{\mathrm{BE}}$ (when both switches $\mathrm{S}_{\mathrm{BE} 1}$ and $\mathrm{S}_{\mathrm{BE} 2}$ are $\mathrm{ON}$ ). Next, these currents are linearly combined such that the capacitor $C$ is charged by a current $I_{1}=3 I_{\mathrm{PTAT}}-0.5 I_{\mathrm{CTAT}}\left(\mathrm{S}_{1}\right.$ is $\mathrm{ON}$, one of $\mathrm{S}_{\mathrm{BE} 1}$ and $\mathrm{S}_{\mathrm{BE} 2}$ is $\mathrm{ON}$ ) and is discharged by a current $I_{2}=I_{\mathrm{CTAT}}-I_{\mathrm{PTAT}}\left(\mathrm{S}_{1}\right.$ is OFF, both $\mathrm{S}_{\mathrm{BE} 1}$ and $\mathrm{S}_{\mathrm{BE} 2}$ are $\left.\mathrm{ON}\right)$.

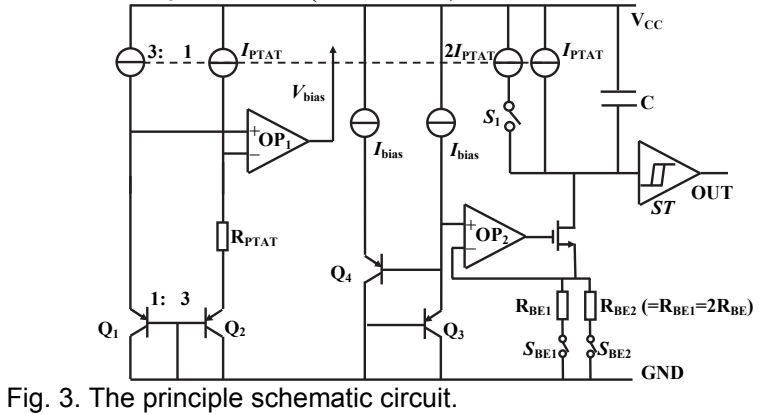

By properly choosing the values of $R_{\text {PTAT }}$ and $R_{B E}$, as well as the nominal value of $V_{\mathrm{BE} 3}$, a linear duty-cycle versus temperature characteristic can be realized: 


$$
D=a_{0}+a_{1} \vartheta
$$

where $\vartheta$ is the temperature in degree Celsius.

For compatibility with the previous design [1], the sensor was designed such that $a_{0}=0.32$ and $a_{1}=0.0047\left({ }^{\circ} \mathrm{C}\right)^{-1}$. In BICMOS technology, a straightforward implementation of the Fig. 3 circuit resulted in good accuracy. This was because the current mirrors and other precision circuits could be implemented with well-matched bipolar transistors, while MOSFETs were only used as switches and digital logic. In CMOS technology, however, a straightforward implantation would result in very poor accuracy, because of the much large mismatch of MOSFETs. Fortunately, by applying chopping and DEM, this problem can be solved and, as will be shown in the next paragraphs, the resulting accuracy exceeds that of previous designs in bipolar or BICMOS technology.

\section{DESIGN FOR ACCURACY}

In the circuit shown in Fig. 3, the main sources of systematic error are:

$>$ Component mismatch, which induces output spread.

$>$ Process spread in the base-emitter voltage $V_{\mathrm{BE} 3}$.

$>$ Limited current gain $\beta$ of the substrate PNPs,

$>$ Non-linearity of $V_{\mathrm{BE}}$ versus temperature.

In this section we will discuss ways to reduce the effects of these error sources one by one. The effects of noise will be discussed in section VI together with the experimental results.

\section{A. Component mismatches}

When designing precision sensors in CMOS technology, component mismatch is the main non-ideality to be taken into account. In our design, this will, for instance, give rise to errors in the gain of the various current mirrors, thus causing the ratios between the various charging and discharging currents to spread. Moreover, mismatch will cause offset voltages in the op-amps $\mathrm{OP}_{1}$ and $\mathrm{OP}_{2}$. These offset voltages are connected in series with our basic signals $\Delta V_{\mathrm{BE}}$ and $V_{\mathrm{BE}}$ and thus directly reduce sensor accuracy. In order to prevent this, the effects of op-amp offset and $1 / f$ noise are mitigated by the use of chopping. In addition, errors in current-mirror gain, as well as in the ratio of resistances and in the emitter areas of the substrate PNPs are mitigated by applying DEM. Since some ill-defined voltages will be dropped across the DEM switches in block $\mathrm{S}_{\mathrm{B} 2}$ (Fig.4), which are used to interchange $\mathrm{Q}_{1}$ and $\mathrm{Q}_{2}$, Kelvin connections are used to accurately sense $\Delta V_{\mathrm{BE}}$ [14], [26]. The DEM and chopping-state machines are self-clocked (by the output of the Schmitt trigger ST), and so no external clock is required. The ratio $R_{\mathrm{BE}} / R_{\mathrm{PTAT}}$ is made accurate by using large devices and careful layout.

As shown in Fig. 4, seven identical PTAT current sources are used to bias $\mathrm{Q}_{1}$ and $\mathrm{Q}_{2}$, as well as to charge and discharge the capacitor $\mathrm{C}$. Therefore, a DEM cycle with at least seven states is required. Furthermore, four identical PNP transistors $\mathrm{Q}_{1}$ and $\mathrm{Q}_{2}$ were used to realize an emitter ratio of three. $\mathrm{A}$ complete DEM cycle of these transistors thus requires four steps. Lastly, the op-amps need to be chopped and the nominally identical $R_{B E}$ resistors need to be swapped. To satisfy all these requirements, an extra dummy current source was added to the circuit (not shown in Fig. 4) and a DEM cycle with eight states was chosen. During each DEM cycle the following actions take place:

$>$ the current sources are rotated once,

$>$ the four BJTs are rotated twice,

$>$ the $\mathrm{R}_{\mathrm{BE}}$ resistors are swapped four times,

$>$ the Op-amps are chopped four times.

Rotating all four groups of components one by one, so that each possible permutation would occur, would require 256 periods. This would be quite time and energy consuming, and the temperature of interest could vary quite significantly during such a long procedure. As one of the main innovations presented in this paper, all four groups of components are rotated concurrently, which significantly reduces the required number of DEM states. This means that not all possible permutations of component configurations are implemented. However, detailed analysis shows that rotating all four groups of components simultaneously is enough to cancel all firstorder mismatch errors, leaving only the much smaller secondorder errors.

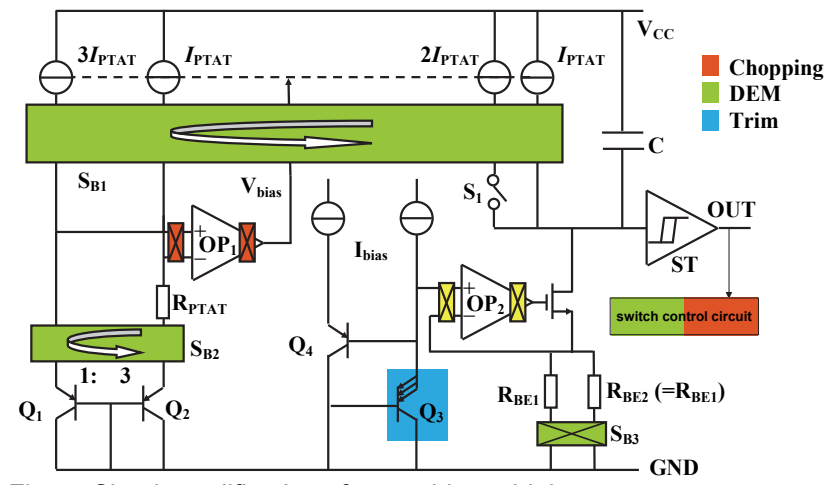

Fig. 4. Circuit modifications for reaching a higher accuracy.

\section{B. Process spread in $V_{B E 3}$}

The second most important error source is the effect of process spread on the base-emitter voltage $V_{\mathrm{BE} 3}[11]$ of $\mathrm{Q}_{3}$. In the selected CMOS technology, the maximum deviation in this voltage amounts to about $\pm 15 \mathrm{mV}$, resulting in an unacceptable temperature error of about $\pm 4 \mathrm{~K}$. This deviation can be corrected by trimming both the bias current and the emitter area of $\mathrm{Q}_{3}$. When resistor spread is also taken into account, the required peak-to-peak trimming range is about $10 \mathrm{~K}$. To correct for this, a trimming scheme with a worst-case (largest) trimming step of about $50 \mathrm{mK}$ (see section IV) has been implemented.

\section{Limited current gain}

Another source of error and spread is the finite current gain $\beta$ of the substrate PNPs (about 25 at room temperature). To reduce this error, an extra current source (Fig. 4), which is not included in the DEM scheme, and a substrate PNP $\left(\mathrm{Q}_{4}\right)$ are used to implement a simple beta-compensation scheme.

\section{Non-linearity of $V_{\mathrm{BE}}$}

In order to partially compensate for the nonlinearity of $V_{\mathrm{BE}}$ versus temperature, the current sum $\left(I_{1}+I_{2}\right)$ has been designed to be slightly proportional to temperature [11] [26]. 


\section{CiRCUIt DEsign}

In this section, key aspects of the circuit-level implementation of the CMOS temperature sensor are presented.

\section{A. Current mirrors and current sources}

To generate the PTAT currents ((Fig. 4), a wide-swing cascoded current mirror [27] has been used. Its large output impedance ensures that $I_{\mathrm{PTAT}}$ remains constant during the charging and discharging of the modulator's timing capacitor C. This ensures that the sensor has a low supply-voltage sensitivity.

\section{B. Op-amps}

The finite gain of the amplifiers $\mathrm{OP}_{1}$ and $\mathrm{OP}_{2}$ causes errors in $I_{\text {PTAT }}$ and $I_{\text {CTAT }}$, respectively. In order to keep the resulting temperature-sensor errors below, for instance, $50 \mathrm{mK}$, the gains of $\mathrm{OP}_{1}$ and $\mathrm{OP}_{2}$, must be larger than $90 \mathrm{~dB}$ and $70 \mathrm{~dB}$, respectively. Moreover, the amplifiers must be able to handle input voltages $\left(V_{\mathrm{BE}}\right)$ down to about $0.3 \mathrm{~V}$ at $130^{\circ} \mathrm{C}$. Both requirements are met by implementing $\mathrm{OP}_{1}$ and $\mathrm{OP}_{2}$ as foldedcascode amplifiers with PMOS input pairs [28].

\section{Schmitt trigger}

The Schmitt Trigger (ST) is based on the use of two inverters in series, with a positive feedback path that controls the threshold voltages of the first inverter [29]. In order to make the swing range as large as possible, the threshold voltage $V_{1}$ and $V_{2}$ (see Fig. 1 (b)) are chosen as close as possible to the corresponding rail voltages, which are:

$$
\begin{aligned}
& V_{1}=V_{\mathrm{TH} \_\mathrm{N}} \\
& V_{2}=V_{\mathrm{CC}}-\left|V_{\text {TH_P }}\right|
\end{aligned}
$$

where $V_{\mathrm{TH} \mathrm{N}}$ and $V_{\mathrm{TH} \mathrm{P}}$ are the threshold voltages of the input invertor of, an NMOS transistor and a PMOS transistor, respectively. The large voltage swing range (about $V_{C C}-2 \mathrm{~V}$ ) at the input of the ST ensures that its input-referred noise has negligible impact on the duty-cycle. By using a large capacitor $(C \sim 150 \mathrm{pF})$, the modulator's oscillation frequency is designed to be low enough (less than $7 \mathrm{kHz}$ ) to ensure that the error caused by the ST's own switching time (a few nanoseconds) is less than $10 \mathrm{mK}$.

\section{Calibration}

An 8-bit trimming network, consisting of a switchable array of PNPs, was used to adjust the base-emitter voltage of $\mathrm{Q}_{3}$ (in Fig. 4) and to compensate for process spread. The base-emitter voltage can be trimmed, starting from its minimum value, with increments in a range of $0 \mathrm{mV}$ to $40 \mathrm{mV}$, with a worst-case (largest) step size of about $50 \mathrm{mK}$. After calibration, the trim code is stored by zapping Zener diodes that form a reliable and low-cost on-chip memory.

\section{Signal AVERAgING}

Due to the application of DEM and chopping in the circuit, the presence of component mismatch means that the dutycycle of the sensor's output will vary from period to period. However, the output signal repeats every eight periods, which is the period of a full DEM cycle. In order to achieve an accurate temperature measurement, the sensor's output must be properly processed, as will be discussed in this section.

Fig. 5 shows the output signal of the temperature sensor over a full DEM cycle. A microcontroller can measure the time intervals $t_{\mathrm{L} 1}, t_{\mathrm{H} 1} ; t_{\mathrm{L} 2}, t_{\mathrm{H} 2}$ etc. relative to its own clock frequency. As discussed in Section III-A, systematic errors due to component mismatch and offset are compensated by averaging them over eight successive periods of the duty-cycle modulator. This signal-processing step is performed by the user, who must, therefore, be aware that the use of incomplete DEM cycles will result in a significant loss of accuracy. However, there are various ways in which the sensor's output can be averaged, as will be discussed below.

\section{A. First type of averaging}

A first type of averaging involves computing the duty-cycle of each period and then averaging the results. This yields the average value $D_{\text {avg1 }}$ as:

$$
D_{\text {avgl }}=\sum_{i=1}^{8}\left(t_{\mathrm{Hi}} /\left(t_{\mathrm{Hi}}+t_{\mathrm{Li}}\right)\right) / 8
$$

where $i$ is the order of the period in one DEM cycle (Fig. 5).

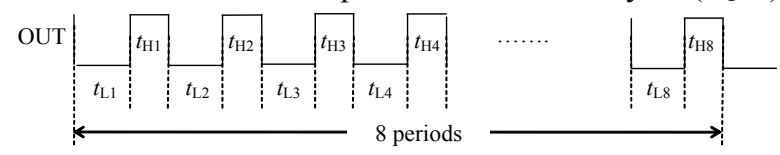

Fig. 5. The output signal of the temperature sensor.

\section{B. Second type of averaging}

A simpler method is to first sum the "High" and "Low" time intervals and then compute the average $D_{\text {avg2 }}$ with a single division as follows:

$$
D_{\text {avg } 2}=\sum_{i=1}^{8} t_{\mathrm{Hi}} / \sum_{i=1}^{8}\left(t_{\mathrm{Hi}}+t_{\mathrm{Li}}\right)
$$

This second type of averaging is equivalent to using an analog low-pass filter to convert the sensor's duty-cyclemodulated output into a DC voltage, which can then be read out by, for instance, a multi-meter. It can also be used in very simple analog temperature-control systems ([6], chapter 7). However, this type of averaging does not completely cancel the mismatch-induced errors, because in the calculation of (6), each period has a different weight: The longer periods will have larger weights than the shorter ones, and thus will contribute more error to the final "averaged" result. Fig. 6 shows the simulated residual temperature errors caused by $1 \mathrm{mV}$ offset in $\mathrm{OP}_{1}$ (Fig. 4) for the two averages $D_{\text {avg1 }}$ and $D_{\text {avg2 }}$, respectively. Here, both residual errors have been normalized to 0 at $27^{\circ} \mathrm{C}$. Note that the average $D_{\text {avg2 }}$ results in much more error, especially at low temperatures. However, for the limited range of $-10^{\circ} \mathrm{C}$ to $+110^{\circ} \mathrm{C}$, the error is still less than $0.1^{\circ} \mathrm{C}$, which is acceptable in many applications.

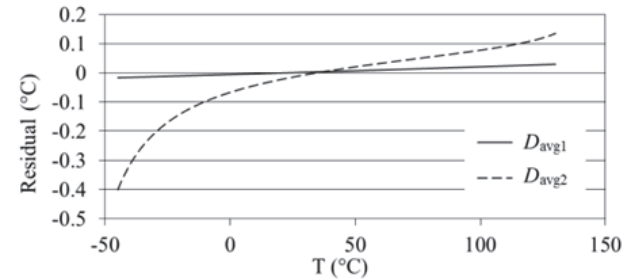

Fig. 6. Simulated residual errors obtained with $D_{\text {avg1 }}$ and $D_{\text {avg2 }}$ for an offset voltage $V_{\text {os } 1}=1 \mathrm{mV}$ of $\mathrm{OP}_{1}$. 


\section{Third method of averaging}

Better temperature-sensing resolution can be obtained by averaging the sensor's output over more than one DEM cycle, because this will reduce the noise bandwidth (see section VI). If this is desired, a third type of averaging can be used to reduce the number of divisions required, while still obtaining high accuracy. This involves calculating the duty-cycle $D_{\text {avg3 }}$ as follows:

a) Suppose that the numbers $N_{\mathrm{L} 1}, N_{\mathrm{H} 1}, N_{\mathrm{L} 2}, N_{\mathrm{H} 2}, \ldots N_{\mathrm{L} 8}, N_{\mathrm{H} 8}$, represent the 16 time intervals $t_{\mathrm{L} 1}, t_{\mathrm{H} 1} ; \ldots t_{\mathrm{L} 8}, t_{\mathrm{H} 8}$ of the sensor's output over one DEM cycle.

b) For the first 8 periods, the values of $N_{\mathrm{L} 1}$ to $N_{\mathrm{H} 8}$ are stored in separate registers.

c) For the $9^{\text {th }}$ period (= the first period of the second DEM cycle), the number $N_{\mathrm{L} 9}$ is added to $N_{\mathrm{L} 1}$, while the number $\mathrm{N}_{\mathrm{H} 9}$ is added to $\mathrm{N}_{\mathrm{H} 1}$. In a similar manner, this is done for the other 14 time intervals of the second DEM cycle.

d) Step c) is repeated for all other DEM cycles.

e) Next, the duty cycle $D_{\text {avg3 }}$ is calculated with an equation similar to (6):

$$
D_{\text {avg3 }}=\sum_{i=1}^{8}\left(N_{\mathrm{Hi}} /\left(N_{\mathrm{Hi}}+N_{\mathrm{Li}}\right)\right) / 8
$$

Note that for $M$ DEM cycles only eight divisions are required. So, as compared to using $D_{\text {avgl}}$, this approach reduces the calculation time by roughly a factor $M$, while its accuracy is as good as when using $D_{\text {avgl }}$.

\section{FABRICATION AND TEst Results}

The temperature sensor is fabricated in standard $0.7 \mu \mathrm{m}$ CMOS technology of On Semiconductor. The die size is $1.7 \mathrm{~mm} \times 1.3 \mathrm{~mm}$ (Fig. 7). In total, the chip has 13 pads. Nine of them are used to store the trimming code determined by wafer-level calibration at room temperature. The other four pads are available to the user and are: $\mathrm{V}_{\mathrm{CC}}, \mathrm{GND}$, OUT and PD (an optional pad for POWER DOWN). The sensors have been packaged in TO18, TO92, TO220, SOT223 and SOIC-8.
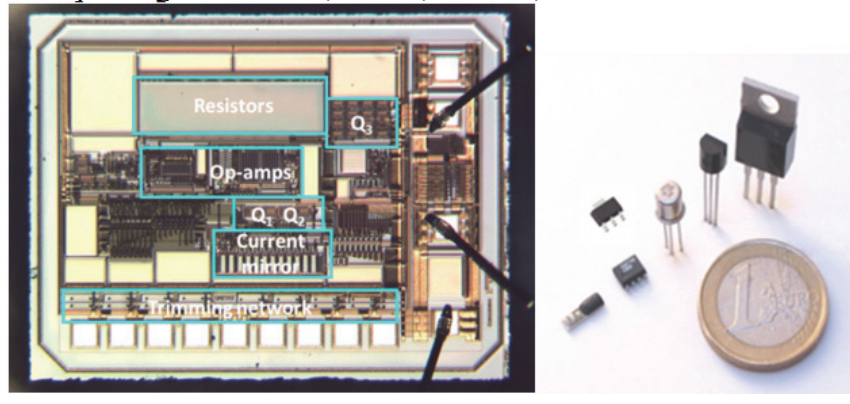

Fig. 7. Chip photo and packages of the temperature sensor.

The sensor has been trimmed at wafer level to counteract the effects of process spread. This is significantly less expensive than trimming individually packaged devices, but relies on the sensor being insensitive to packaging-shift. Without trimming the sensor exhibits about $\pm 5 \mathrm{~K}$ error, which is not acceptable.

\section{A. $\quad$ Test set up}

To characterize the duty cycle versus temperature accurately, the sensor's output is compared with that of a reference sensor. In our case, a Pt100 platinum resistor with an inaccuracy of less than $\pm 20 \mathrm{mK}$ over the full temperature range of $-45^{\circ} \mathrm{C}$ to $130^{\circ} \mathrm{C}$, was used as the reference sensor. To ensure that the sensor temperatures were as close as possible to that of the reference sensor, a special set-up was built, as shown in Fig. 8. An ARM processor (STM32F103CBT6) with a $72 \mathrm{MHz}$ counter was used to digitize the time intervals of the sensor output and to calculate the average duty cycle.

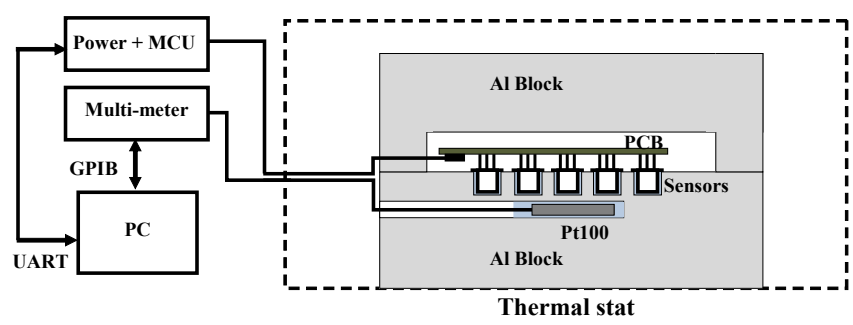

Fig. 8. Measurement set-up for the temperature characterization of the sensors.

\section{B. DEM and averaging}

The sensor's output is a rail-to-rail square-wave voltage. The frequency varies from about $500 \mathrm{~Hz}$ to $7 \mathrm{kHz}$, depending on the supply voltage and temperature, although the exact variation is subject to process spread. Only the duty cycle contains accurate temperature information.

As explained in section III, DEM and Chopping have been applied to achieve an accurate result. To benefit from this, the sensor's duty-cycle should be averaged over eight successive periods in one of the ways described in section V. Finally, the temperature is calculated using (3).

To show the importance of averaging over complete groups of 8 periods, Fig. 9 shows a typical real-time measurement result for each period (dashed line) without any averaging, and the moving average, using (5) over eight periods (solid line). Note that with the dashed line, the results repeat every eight readings, corresponding to the eight states of one DEM cycle, where errors induced by component mismatch are still present. The temperature error of each single period varies from $-2.9 \mathrm{~K}$ to $3.2 \mathrm{~K}$, and these values vary from sample to sample, depending on the specific mismatch. In contrast, averaging over eight periods reduces mismatch-induced errors significantly, to $-0.018 \mathrm{~K}$.

It can be shown that the measurement can be started at an arbitrary transient (up-going or down-going) in a DEM cycle. So, no synchronization is required because any series of eight periods will cover a full DEM cycle. The measurement results discussed in the following text are all based on using the average over eight periods or integer numbers of eight periods.

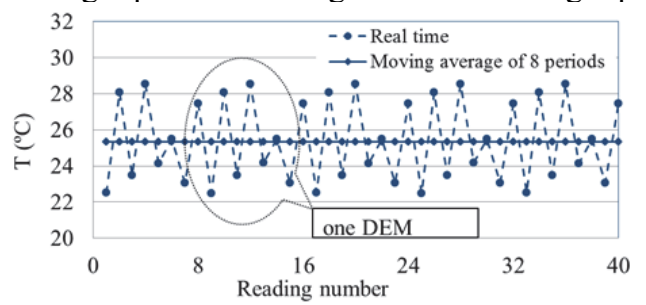

Fig. 9. Measured temperature reading at room temperature $\left(T_{\text {ref }}=25.356^{\circ} \mathrm{C}\right)$. 


\section{Accuracy versus temperature}

To characterize device spread, 36 calibrated samples in (metal) TO-18 packages were tested over the temperature range from $-45^{\circ} \mathrm{C}$ to $130^{\circ} \mathrm{C}$. As an example, Fig. 10 (a) shows the measured temperature errors of 70 samples from two batches after computing the average duty cycle according to (5) or (7) $\left(D_{\text {avg1 }}\right.$ or $\left.D_{\text {avg3 }}\right)$. This figure shows clearly the remaining systematic nonlinearity, which is mainly due to incomplete curvature correction and to the exponential increase of leakage currents at high temperatures.

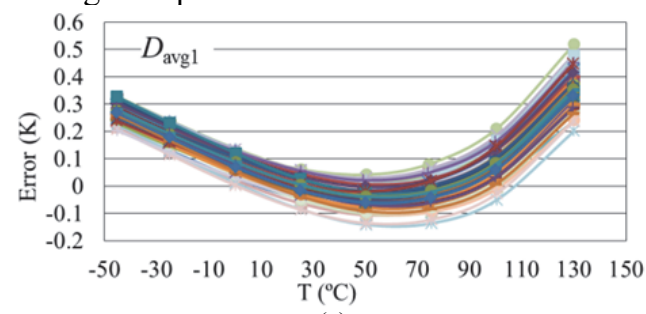

(a)

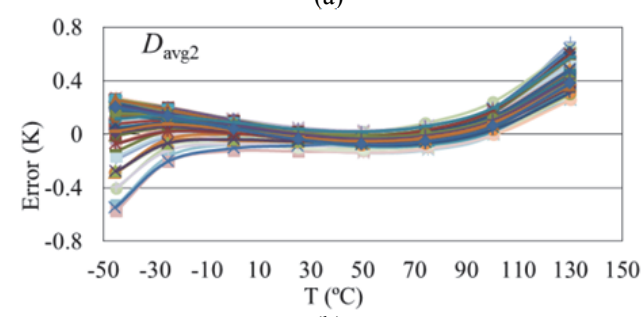

(b)

Fig. 10. Systematic error versus temperature for 70 samples from two batches when the duty cycle is calculated (a) with (5) or (7) ( $D_{\text {avg1 }}$ or $\left.D_{\text {avg3 }}, \mathrm{V}_{\mathrm{cC}}=5 \mathrm{~V}\right)$ and (b) with (6) $\left(D_{\text {avg2 }}\right)$.

Fig. 10 (b) shows the measured total error for the case when, with the same measurement data, the average duty cycle is calculated with the simpler $(6)\left(D_{\text {avg2 }}\right)$. In agreement with Fig. 6 , there is significantly more error at low temperatures. However, for the temperature range from $0^{\circ} \mathrm{C}$ to $110^{\circ} \mathrm{C}$, this error is still less than $0.2^{\circ} \mathrm{C}$. Note that this error is larger than the simulated error shown in Fig. 6 and varies from sample to sample, depending on the specific amounts and combinations of offset and component mismatch that are present.

The measurement results depicted in Fig. 10 (a) show that the spread between the samples is very small. Therefore, the systematic non-linearity can further be reduced by fitting the sensor's residual nonlinearity with a higher-order polynomial. After a least-squares fit on the measurement results shown in Fig. 10 (a), the relationship between the average duty cycle $D$ and temperature $\vartheta$, is found to satisfy the following third-order polynomial:

$$
D=a_{0}+a_{1} \vartheta+a_{2} \vartheta^{2}+a_{3} \vartheta^{3}
$$

where $a_{0}=0.32 ; a_{1}=4.68 \times 10^{-3} /\left({ }^{\circ} \mathrm{C}\right) ; a_{2}=7.03 \times 10^{-8} /\left({ }^{\circ} \mathrm{C}\right)^{2}$; $a_{3}=1.10 \times 10^{-9} /\left({ }^{\circ} \mathrm{C}\right)^{3}$ and $\vartheta=$ temperature in ${ }^{\circ} \mathrm{C}$.

Fig. 11 shows that the residual inaccuracy after computing $D_{\text {avg1 }}$ and applying (8) is less than $\pm 0.2^{\circ} \mathrm{C}$ from $-45^{\circ} \mathrm{C}$ to $130^{\circ} \mathrm{C}$.

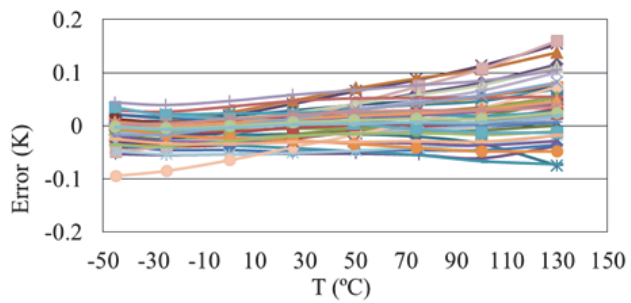

Fig. 11 Same data as depicted in Fig.10 (a), but when using a thirdorder correction of the results, according to (8).

\section{Noise}

At a stable temperature of about $25^{\circ} \mathrm{C}$, the sensor's noise was measured by logging the results of 360000 measurements, where each measurement is based on averaging over eight periods. A microcontroller with a $72 \mathrm{MHz}$ sampling frequency was used to digitize the time intervals. As shown in Fig. 12, for the minimum measurement time $t_{\mathrm{m}}$ of $1.8 \mathrm{~ms}$ ( 8 periods), the resolution is about $3 \mathrm{mK}$ (rms). The sensor's energy efficiency can be benchmarked with the help of the resolution Figure of Merit (FoM) $F$, which is defined as follows [30]:

$$
F=E \cdot s^{2}
$$

where $E$ is the energy consumed during one complete measurement (one DEM cycle) and $s$ is the sensor's resolution (standard deviation). For a supply voltage of $3.3 \mathrm{~V}$, a supply current of $60 \mu \mathrm{A}$, and a measurement time $t_{\mathrm{m}}$ of $1.8 \mathrm{~ms}(8$ periods), the energy $E$ for one measurement is only $356 \mathrm{~nJ}$. The sensor's resolution FoM is $3.2 \mathrm{pJK}^{2}$, which is much smaller than that of other products in the market (see table II). Even including recent research results, this FoM represents the state of the art for BJT-based temperature sensors [10], [30].

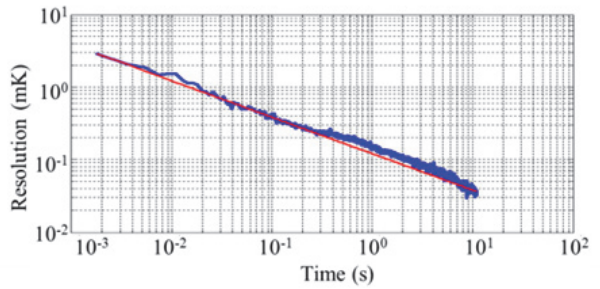

Fig. 12. Measured resolution (standard deviation) versus measurement time (72MHz sampling frequency).

In sensor systems where a slower microprocessor is used to digitize the time intervals, the quantization noise due to the limited sampling speed should also be taken into account. For this, the reader is referred to [30].

\section{E. DC Supply-voltage sensitivity}

Fig. 13 shows the change of the sensor's error versus the DC supply voltage for three temperatures, referred to the errors at $V_{\mathrm{CC}}=5 \mathrm{~V}$. Over the whole temperature range, the output varies by less than $0.1^{\circ} \mathrm{C}$ over the supply-voltage range from $2.5 \mathrm{~V}$ to $5.5 \mathrm{~V}$. 


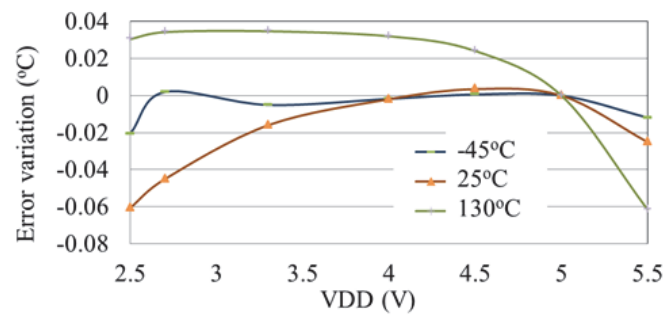

Fig. 13. Variation of sensor output with change of DC supply voltage, relative to its output with a $5 \mathrm{~V}$ supply.

\section{F. Packaging and packaging shift}

To meet different market requirements, the new temperature sensor has been packaged in various types of packages (Fig. 8). Due to differences in the thermal expansion coefficients of the various materials involved (silicon die, die attachment and metal substrate), some mechanical stress remains after the high-temperature packaging process. Plastic packages induce much more mechanical stress than metal-can packages (i.e. TO-18) because they use an epoxy resin that completely covers the chip [24], [25]. Due to the piezo-junction effect, this packaging-induced stress will change the base-emitter voltage $V_{\mathrm{BE} 3}$ (Fig. 4) and thus induce extra error in the sensor's output. As shown in [23] and [25], vertical PNPs are much less stress sensitive than vertical NPNs. So, the sensor presented here should exhibit less packaging shift and better stability than the one described in [11]. Packaging shift, as due to mechanical stress, has been investigated for the five different packages. The average values of this shift at room temperature for TO-18, TO-92, TO-220 are listed in Table I, together with values for a previous BiCMOS design in TO-18 and TO-92 packages [1].

Test results for other plastic packages (SOT223 and SOIC) are similar to those for TO92 and TO220 in Table I. These results show that the room temperature error induced by the metal-can package (TO-18) is almost negligible. The plastic packages induce a positive shift, which is much smaller than that of a previous product [1]. These results demonstrate the remarkable improvement that can be achieved when vertical PNPs rather than NPNs are used as sensing elements.
TABLE I

MEASURED PACKAGING SHIFT FOR THREE TYPES OF PACKAGES COMPARED WITH THE SHIFT IN THE PRODUCTS DESCRIBED IN ERROR!

\begin{tabular}{|c|c|c|c|c|c|}
\multicolumn{7}{|c|}{ REFERENCE SOURCE NOT FOUND.] } \\
\hline $\begin{array}{c}\text { TO-18 } \\
\text { this work }\end{array}$ & $\begin{array}{c}\text { TO-92 } \\
\text { this work }\end{array}$ & $\begin{array}{c}\text { TO-220 } \\
\text { this work }\end{array}$ & $\begin{array}{c}\text { TO-18 } \\
{[1]}\end{array}$ & $\begin{array}{c}\text { TO-92 } \\
{[1]}\end{array}$ \\
\hline Number of sensors & 36 & 18 & 9 & 18 & 18 \\
\hline Mean error $\left({ }^{\circ} \mathrm{C}\right)$ & 0.004 & 0.044 & 0.053 & -0.026 & 0.38 \\
\hline Spread $(3 \sigma)\left({ }^{\circ} \mathrm{C}\right)$ & 0.06 & 0.13 & 0.06 & 0.31 & 0.35 \\
\hline
\end{tabular}

: The plastic packages employ a stress-relieving die coating.

\section{G. Stability}

Long-term stability tests have been performed by a certified qualification company (Tempcontrol I.E.P. B.V.). Eight sensors (never powered-on after wafer calibration) were inserted in a metal tube, filled with thermal conductive compound. This tube was put in a water bath, whose temperature was regulated at $22^{\circ} \mathrm{C}$ with an inaccuracy $<0.5 \mathrm{mK}$. Over 367 days, as shown in Fig. 14, the sensor's output drift was found to be less than $\pm 6 \mathrm{mK}$.

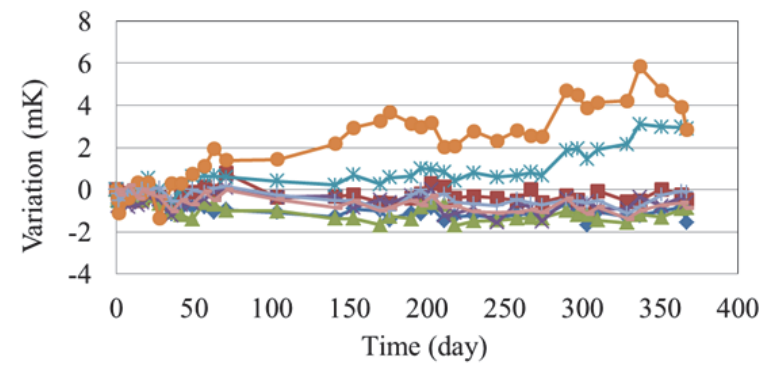

Fig. 14 Variation of temperature output over 367 days for 8 samples at $22^{\circ} \mathrm{C}$.

\section{H. Performance summary and comparison with other products}

Table II summarizes the main features of this design compared to existing products with similar accuracy or with a similar number of pins. A full list of specifications of the final product can be found in [31]. It can be seen that it achieves better accuracy, resolution and resolution FoM, as well as higher speed. One of the main reasons for its excellent resolution FoM is that it outputs a quasi-analog signal, whose time intervals are then digitized by a microcontroller. Thanks to this feature, the sensor's energy consumption, and hence, any self-heating effects are extremely low.

TABLE II

COMPARISON WITH OTHER STATE-OF-THE-ART TEMPERATURE SENSORS.

\begin{tabular}{|c|c|c|c|c|c|c|}
\hline & This design & SMT160 [1] & D18B20 [2] & LMT01 [3] & TMP107 [4] & ADT7320 [5] \\
\hline Supply voltage (V) & 2.7 to 5.5 & 4.75 to 7.2 & 3.0 to 5.5 & 2.0 to 5.5 & 1.7 to 5.5 & 2.7 to 5.5 \\
\hline Supply current $(\mu \mathrm{A})$ & 42 to 75 & 180 & 1000 to 1500 (at $5 \mathrm{~V})$ & 34 to 125 & 200 to 400 & 210 to 300 \\
\hline Number of pins & 3 or 4 & 3 & 3 & 2 & 8 & 12 \\
\hline Temperature range $\left({ }^{\circ} \mathrm{C}\right)$ & -45 to 130 & -45 to 130 & -55 to 125 & -50 to 150 & -55 to 125 & -40 to 125 \\
\hline Output signal & DCM & DCM & digital & digital & digital & digital \\
\hline Measurement time (ms) & 1 to 22 & 0.25 to 2 & 94 to 750 & 100 & 12 to 18 & 240 \\
\hline Supply voltage Sensitivity $\left({ }^{\circ} \mathrm{C} / \mathrm{V}\right)$ & 0.1 & 0.1 & 0.1 & 0.13 & 0.1 & 0.1 \\
\hline \multirow{2}{*}{$\begin{array}{c}\text { Best Accuracy }\left({ }^{\circ} \mathrm{C}\right) \\
\left.\text { (Temperature range }\left({ }^{\circ} \mathrm{C}\right)\right)\end{array}$} & $\begin{array}{c}0.1^{1} \\
(-20 \text { to } 60)\end{array}$ & $\begin{array}{c}0.7 \\
(-10 \text { to } 100) \\
\end{array}$ & $\begin{array}{c}0.5 \\
(-10 \text { to } 85)\end{array}$ & $\begin{array}{c}0.5 \\
(-20 \text { to } 90)\end{array}$ & $\begin{array}{c}0.4 \\
\text { (-20 to } 70)\end{array}$ & $\begin{array}{c}0.5 \\
(-10 \text { to } 105) \\
\end{array}$ \\
\hline & $\begin{array}{c}0.3^{1} \\
(-45 \text { to } 130)\end{array}$ & $\begin{array}{c}1.2 \\
(-45 \text { to } 130)\end{array}$ & $\begin{array}{c}2 \\
(-55 \text { to } 125) \\
\end{array}$ & $\begin{array}{c}0.7 \\
(-50 \text { to } 150) \\
\end{array}$ & $\begin{array}{c}0.7 \\
(-55 \text { to } 125) \\
\end{array}$ & $\begin{array}{c}0.66 \\
(-40 \text { to } 125) \\
\end{array}$ \\
\hline $\begin{array}{c}\text { Resolution }\left({ }^{\circ} \mathrm{C}\right) \\
\text { Measurement time }(\mathrm{ms})\end{array}$ & $\begin{array}{c}0.003 \\
1.8\end{array}$ & $\begin{array}{c}0.005 \\
20\end{array}$ & $\begin{array}{c}0.0625 \\
750\end{array}$ & $\begin{array}{c}0.0625 \\
100\end{array}$ & $\begin{array}{c}0.0156 \\
15\end{array}$ & $\begin{array}{c}0.0078 \\
240\end{array}$ \\
\hline Resolution FoM (pJK $\left.{ }^{2}\right)$ & 3.2 & 430 & $1.46 \times 10^{7}$ & $4.38 \times 10^{4}$ & $2.42 \times 10^{3}$ & $8.28 \times 10^{3}$ \\
\hline
\end{tabular}

': The accuracy in these cells is the result using (8) and $D_{\text {avg1 }}$ or $D_{\text {avg3. }}$. 


\section{CONCLUSIONS}

The details of a BJT-based temperature sensor designed and fabricated in $0.7 \mu \mathrm{m}$ CMOS technology have been discussed. The use of a duty-cycle-modulated output signal enables easy interfacing with both digital and analog systems. Its high output data rate makes this sensor well suited to both temperature monitoring and controlling. A high accuracy is achieved by applying DEM and chopping, which significantly reduces the errors caused by CMOS component mismatching. Simultaneously rotating all the component groups during the DEM process, instead of rotating them one after one, reduces the number of DEM periods significantly, making the measurement speed much faster. By applying DEM, the mismatch-induced errors from the various groups of components can be reduced to the second order. To achieve this result, the results of a complete DEM cycle must be averaged. Three different types of averaging have been discussed. They provide different trade-offs between computational speed/complexity and sensing accuracy. Applying substrate PNPs instead of NPNs reduces errors caused by package-induced stress. As a result, the presented sensor has a much better long-term stability than earlier designs. It also facilitates the use of low-cost packaging technologies, which compared to metal-can packaging, typically induce large amounts of mechanical stress.

Measurement results show that this temperature sensor achieves a state of art resolution Figure of Merit, which is better than $\left(3.2 \mathrm{pJK}^{2}\right)$. This makes this sensor highly suited for low-energy applications. After wafer calibration at room temperature, the sensor's accuracy is better than $0.1^{\circ} \mathrm{C}\left(-20^{\circ} \mathrm{C}\right.$ to $\left.60^{\circ} \mathrm{C}\right)$ and $0.3^{\circ} \mathrm{C}\left(-45^{\circ} \mathrm{C}\right.$ to $\left.130^{\circ} \mathrm{C}\right)$, respectively. Packageinduced errors were found to be less than $0.1^{\circ} \mathrm{C}$ at room temperature. Measurements over 367 days show a long-term drift less than $6 \mathrm{mK}$.

\section{ACKNOWLEDGMENT}

The authors gratefully ackowledge Mr. Jaap van Wensveen of Tempcontrol Industrial Electronic Products B.V., the Netherlands for performing the long term stability test.

\section{REFERENCES}

[1] Smartec BV, Datasheet SMT 160-30 digital temperature sensor, http://www.smartec-sensors.com.

[2] Maxim Integrated, datasheet of D18B20, $\mathrm{http}: / /$ datasheets.maximintegrated.com/en/ds/DS18B20.pdf.

[3] Texas Instruments, datasheet of LMTO1, http://www.ti.com/lit/ds/symlink/lmt01.pdf

[4] Texas Instruments, datasheet of TMP107, http://www.ti.com/lit/ds/symlink/tmp 107.pdf.

[5] Analog Devices, datasheet of ADT7320, http://www.analog.com/media/en/technical-documentation/datasheets/ADT7320.pdf

[6] G.C.M. Meijer (edited), "Smart Sensor Systems", Wiley, 2008, Chap. 7.

[7] V.C. Gungo and G.P. Hancke, "Industrial Wireless Sensor Networks challenges, design principles and technical approaches," IEEE Trans. Ind. Electron., vol. 56, no. 14, pp. 4258-4265, Oct. 2009.

[8] P. Li, Y. Wen Z. Zhang and S. Pan, "A high-efficiency management circuit using multi winding up conversion current transformer for power-line energy harvesting," IEEE Trans. Ind. Electron., vol. 62, no. 10, pp. 6237-6335, Oct. 2015.

[9] J.P. Carmo, L.M. Gonçalves, and J.H. Correia, "Thermoelectric micro converter for energy harvesting systems," IEEE Trans. Ind. Electron., vol. 57, no. 3, pp. 861-867, Mar. 2010.

[10] A. Heidari, G. Wang, K. Makinwa and G.C.M. Meijer, "A BJT-based CMOS Temperature Sensor with a $3.6 \mathrm{pJK}^{2}$ Resolution FOM", ISSCC Dig. Tech. Papers, pp.224-225, Feb. 2014.

[11] G.C.M. Meijer, R. van Gelder, V. Nooder, J. van Drecht and H.M.M. Kerkvliet, "A three-terminal integrated temperature transducer with microcomputer interfacing", Sensors and Actuators, vol. 18, pp. 195206, June 1989.

[12] M.A.P. Pertijs, K.A.A. Makinwa and J.H. Huijsing, "A CMOS temperature sensor with a $3 \sigma$ inaccuracy of $\pm 0.1{ }^{\circ} \mathrm{C}$ from $-55^{\circ} \mathrm{C}$ to $125^{\circ} \mathrm{C}^{\prime}$, IEEE J. Solid-State Circuits, vol. 40, no.12, pp. 2805-2815, Dec. 2005.

[13] K. Souri, Y. Chae and K.A.A. Makinwa, "A CMOS temperature sensor with a voltage calibrated inaccuracy of $\pm 0.15^{\circ} \mathrm{C}(3 \sigma)$ from $-55^{\circ} \mathrm{C}$ to $125^{\circ} \mathrm{C}^{\prime}$, IEEE J. Solid-State Circuits, vol. 48, no.1, pp. 292-301, Jan. 2013.

[14] S. Shalmany, Dieter Draxelmayr and K.A.A. Makinwa, "A Micro Power Battery Current Sensor with $\pm 0.03 \%(3 \sigma)$ Inaccuracy from $-40^{\circ} \mathrm{C}$ to $+85^{\circ}$ C", ISSCC Dig. Tech. Papers, pp. 386-387, Feb. 2013.

[15] A.L. Aita, M.A.P. Pertijs, K.A.A. Makinwa, J.H. Huijsing, G.C.M. Meijer, "Low-power CMOS smart temperature sensor with a batchcalibrated inaccuracy of $\pm 0.25^{\circ} \mathrm{C}( \pm 3 \sigma)$ from $-70^{\circ} \mathrm{C}$ to $130^{\circ} \mathrm{C} "$, IEEE Sensors J., vol. 13, no. 5, pp. 1840-1848, May 2013.

[16] X. Pu, M. Ash, K. Nagaraj, J. Park, S. Vu, P. Kimelman and S. De La Haye, "A $\pm 0.4^{\circ} \mathrm{C}$ accurate high-speed remote junction temperature sensor with digital Beta correction and series-resistance cancellation in 65nm CMOS”, Symposium on. VLSI Circuits (VLSIC), pp. 214-215, June 2013

[17] K. Souri, Y. Chae, F. Thus and K.A.A. Makinwa, "A $0.85 \mathrm{~V}$ 600nW All-CMOS Temperature Sensor with an Inaccuracy of $\pm 0.4^{\circ} \mathrm{C}(3 \sigma)$ from $-40^{\circ} \mathrm{C}$ to $125^{\circ} \mathrm{C}$ ", ISSCC Dig. Tech. Papers, pp.222-223, Feb. 2014.

[18] C. Azcona, B. Calvo, N. Medrano and S. Celma, "1.2V-0.18 $\mu \mathrm{m}$ CMOS Temperature Sensor With Quasi-Digital Output for portable Systems", IEEE trans. Instrumentation and Measurement, Vol. 64, no.9, pp. 25652573, Sept. 2015.

[19] R. Quan, U. Sonmez, F. Sebastiano, K.A.A. Makinwa, "A $4600 \mu \mathrm{m}^{2}$ $1.5^{\circ} \mathrm{C}(3 \sigma) 0.9 \mathrm{kS} / \mathrm{s}$ Thermal-Diffusivity Temperature Sensor with VCOBased Readout", ISSCC Dig. Tech. Papers, pp.488-489, Feb. 2015.

[20] S. Huber, A. Laville, and C. Schott, "A Bridge-Type Resistive Temperature Sensor in CMOS Technology with Low Stress Sensitivity", Proc. IEEE Sensors, pp.1455-1458, Nov. 2014.

[21] P. Chen, C. Chen, Y. Peng, K. Wang, and Y. Wang, "A Time-Domain SAR Smart Temperature Sensor With Curvature Compensation and a $3 \sigma$ Inaccuracy of $0.4^{\circ} \mathrm{C} \sim+0.6^{\circ} \mathrm{C}$ Over a $0^{\circ} \mathrm{C}$ to $90^{\circ} \mathrm{C}$ Range", IEEE $J$. Solid-State Circuits, vol. 45, no.3, pp. 600-609, Mar. 2010.

[22] P. Park, D. Ruffieux, and K.A.A. Makinwa, "A Thermistor-Based Temperature Sensor for a Real-Time Clock With $\pm 2 \mathrm{ppm}$ Frequency Stability", IEEE J. Solid-State Circuits, vol. 50, no.7, pp. 1571-1580, July 2015.

[23] G.C.M. Meijer, G. Wang and F. Fruett, "Temperature sensors and voltage references implemented in CMOS technology", IEEE Sensors J., Vol. 1, no.3, pp 225-234, Oct. 2001

[24] J. F. Creemer, F. Fruett, G.C.M. Meijer and P. J. French, "The Piezojunction Effect in Silicon sensors and Circuits and its Relation to Piezoresistance", IEEE Sensors J., Vol. 1, no.2, pp 98-108, Aug. 2001.

[25] F. Fruett and G.C.M. Meijer, "The Piezo-junction Effect in Silicon Integrated Circuits and Sensors", Kluwer Academic Publishers, Boston/Dordrecht/London, 2002.

[26] M.A.P. Pertijs and Johan Huijsing, "Precision Temperature Sensors in CMOS technology", Springer, 2006, pp.267-268.

[27] D.A. Neamen, "Electronic Circuit Analysis and Design", Irwin Professional Publishing, 1996, pp. 606-607.

[28] M.C. Schneider and C. Galup-Montoro, "CMOS Analog Design Using All-Region MOSFET Modeling”, Cambridge University Press, 2010, pp. 306-320.

[29] I.M. Filanovsky and H. Baltes, "CMOS Schmitt trigger design", IEEE Trans. on Circuits and Systems I: Fundamental Theory and Applications, I. vol. 41, issue 1, pp46-49, Jan. 1994. 
[30] K.A.A. Makinwa, "Smart Temperature Sensors in Standard CMOS", Proc. Euro-sensors, pp. 930 - 939, Sept. 2010.

[31] Smartec BV, Datasheet SMT172 digital temperature sensor, http://www.smartec-sensors.com.

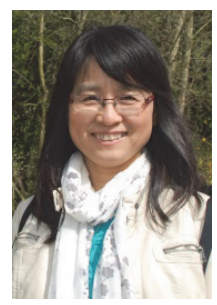

Guijie Wang was born in LuoYang, China. She received the B.S. degree in Physics and M.S. degree in Electronical Engineering from the NanKai University in 1984 and 1987, respectively. She received her $\mathrm{PhD}$ in Electronical Engineering from Delft University of Technology in 2005.

She has been working as research and design engineer in Smartec, the Netherlands. The main focus is on BJT-based CMOS temperature sensor, the recent result has been successively commercialized as an important product (Smartec, SMT172). She is also busy with technical support for customers. Now she is working on BJT-based temperature sensor in $0.18 \mu \mathrm{m}$ CMOS technology.

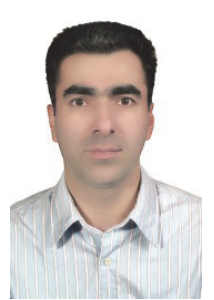

Ali Heidari was born in Langroud, Iran, in 1971. He received the B.S. degree from Iran University of Science and Technology in 1992 and the M.S degree in electrical engineering from Tehran University in 1995. In 2010 he received the PhD degree also in electrical engineering, from Delft University of Technology, The Netherlands. After finalizing his $\mathrm{PhD}$ in 2010 he is a member of academic staff in electrical engineering at Guilan University, Rast, Iran. He is also a guest researcher at TU Delft where he is working on integrated temperature sensors in CMOS technology. His main interest is analog and mixed signal integrated circuit design.

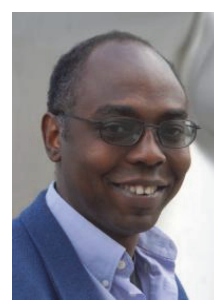

Kofi A. A. Makinwa (M'97-SM'05-F'11) received the B.Sc. and M.Sc. degrees from Obafemi Awolowo University, Nigeria in 1985 and 1988 respectively. In 1989, he received the M.E.E. degree from the Philips International Institute, The Netherlands and in 2004, the Ph.D. degree from Delft University of Technology, The Netherlands. $\mathrm{He}$ is currently an Antoni van Leeuwenhoek Professor with the Faculty of Electrical
Engineering, Computer Science and Mathematics, Delft University of Technology, which he joined in 1999. From 1989 to 1999, he was a Research Scientist with Philips Research Laboratories, Eindhoven, the Netherlands, where he worked on interactive displays and on frontends for optical and magnetic recording systems. His main research interests are in the design of precision mixed-signal circuits, sigmadelta modulators, smart sensors and sensor interfaces. This has resulted in 10 books, 25 patents and over 200 technical papers.

Prof. Makinwa is on the program committees of the International Solid-State Circuits Conference (ISSCC), the VLSI Symposium, the European Solid-State Circuits Conference (ESSCIRC) and the Advances in Analog Circuit Design (AACD) workshop. He has also served as a guest editor of the Journal of Solid-State Circuits (JSSC) and as a distinguished lecturer of the IEEE Solid-State Circuits Society. For his doctoral research, he was awarded the 2005 Simon Stevin Gezel Award from the Dutch Technology Foundation. He is a corecipient of several best paper awards, from the JSSC, ISSCC, Transducers and ESSCIRC among others. He is an alumnus of the Young Academy of the Royal Netherlands Academy of Arts and Sciences and an elected member of the IEEE Solid-State Circuits Society AdCom, the society's governing board.

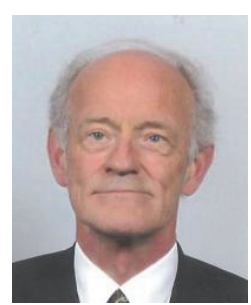

Gerard C.M. Meijer (M'94-SM'98) received his M.Sc. and Ph.D. degrees in Electrical Engineering from the Delft University of Technology, Delft, The Netherlands, in 1972 and 1982, respectively. Since 1972 he has been a member of the Research and teaching staff of Delft University of Technology, where he is a professor, engaged in research and teaching on Analogue Electronics and Electronic Instrumentation.

Since 1984, he has been consultant for industrial companies and research institutes. In 1996 he co-founded the company SensArt, where he is consultant in the field of sensor systems. In 1999 the Dutch Technology Foundation STW awarded him with the honoree degree "Simon Stevin Meester" and in 2001 he was awarded the Anthony van Leeuwenhoek chair at TU Delft. In addition to many journal and conference papers, Meijer is also author and editor of books in the field of sensor systems, published by IOP, Kluwer, Springer and Wiley.

Prof. Meijer is a member of the IEEE Industrial Electronics Society and a senior member of the IEEE Solid State Circuit Society. 